\title{
A prospective study of functional outcome of lumbar prolapsed intervertebral disc managed with surgical decompression
}

\author{
Faiyajuddin Ansari ${ }^{1}$, Sanjay Kumar Barik ${ }^{2 *}$, Akanksha Pokale ${ }^{3}$, Kartik Ghate ${ }^{4}$ \\ $\left\{1,3,4\right.$ Final Year Post Graduate Resident, ${ }^{2}$ Assistant Professor, Department of Orthopaedics $\}$ \{ ${ }^{3}$ Final Year Post Graduate Resident, Department \\ of Radiology\} Vilasrao Deshmukh Government Institute of Medical Science, Near Rajasthani Marwadi High School, Latur 413512, \\ Maharashtra, INDIA. \\ Email: sanjaybarik4u@gamil.com
}

Abstract Background: In India, nearly 60 percent of the people have significant back pain at some time or other in their life and the most common cause of back pain with radiculopathy is lumbar intervertebral disc herniation. Treatment involves both surgical and non-surgical methods, with most responding to conservative management and only $10 \%$ require surgery. In our study, surgical treatment was done using laminectomy with discectomy. We wish to assess the functional outcome of the patients who underwent surgery and its complications. Materials and methods- 30 patients were included in the study and were followed up upto 1 year postoperatively. We assessed the outcome of each patient with back pain functional scale (BPFS) of Strafford et al. scoring system at the time of discharge, 6 months and 1 year follow up. Results- we found that males who were heavy manual labourers had higher incidence of PIVD. Left side was most commonly involved, L4-5 level being most common. Majority of the patients (73.3\%) presented with protrusion followed by extrusion $(16.7 \%)$ and sequestration (10\%). According to Back Pain Functional Scale, good results were found in $20(66.7 \%)$ cases, fair result in $6(20 \%)$ cases and poor results in $4(13.3 \%)$ cases at discharge. During 6 months follow-up period, good results were found in $25(83.3 \%)$ cases, fair result in $5(16.7 \%)$ cases and none of the patients had poor results (Graph 6). During 1 year followup period, all patients showed good results. Conclusion- our study established that laminectomy with discectomy has a good functional outcome at mid term follow up and leads to significant improvement in patient's quality of life.

Keywords- posterior intervertebral disc prol3s21qeq1apse, radiculopathy, back pain, laminectomy.

*Address for Correspondence:

Dr Sanjay Kumar barik, Assistant professor, Department of orthopaedic, Vilasrao Deshmukh Government Institute of Medical Science, Near Rajasthani Marwadi High School, Latur 413512, Maharashtra, INDIA.

Email: sanjaybarik4u@gamil.com

Received Date: 07/11/2019 Revised Date: 12/12/2019 Accepted Date: 26/01/2020

DOI: https://doi.org/10.26611/1031531

This work is licensed under a Creative Commons Attribution-NonCommercial 4.0 International License. (oc)) EY-NC

\begin{tabular}{|l|l|}
\hline \multicolumn{2}{|c|}{ Access this article online } \\
\hline Quick Response Code: & Website: \\
& www.medpulse.in \\
\cline { 2 - 2 } & \\
\hline
\end{tabular}

\section{INTRODUCTION}

In India, nearly 60 percent of the people have significant back pain at some time or other in their life ${ }^{1}$. Herniated lumbar disk is the most common specific cause of low back pain. Although laminectomies were performed for low backache, the credit for identifying the intervertebral disc herniation to being the cause for sciatica goes to Mixter and Barr's classical article in 1934, and they performed laminectomy with discectomy to relieve sciatica ${ }^{2}$. Young and middle-aged individuals are the most frequent sufferers of this condition ${ }^{3}$. At one end of spectrum, treatment is conservative management in the form of rest, physiotherapy, analgesics, other minimally invasive management in form of epidural steroid and at other extreme end of spectrum is removal of prolapsed intervertebral disc. The decision to treat any condition depends upon an understanding of the natural history of the disease process. The natural history of a lumbar hernia of 
the nucleus pulposus (HNP) is not fully known and clear indications for operative intervention cannot be established from the literature. Back surgery rates, however, increase almost linearly with the per capita supply of orthopaedic and neurosurgeons in the country ${ }^{4}$ Our aim was to assess the outcome of the patient undergoing laminectomy with discectomy, and complications of the surgery (if any). We used back pain functional scale (BPFS) of Strafford et al. scoring system at the time of discharge, 6 months and 1 year follow up, to assess the functional outcome of the surgery.

\section{MATERIALS AND METHODS}

A hospital based prospective study was conducted with 30 patients to evaluate functional outcome of lumbar prolapsed intervertebral disc managed with surgical decompression. The study was conducted in tertiary care centre in Latur, Maharashtra over a period of 18 months from December 2017 to May 2019. We included patients above age 18 years, with less than 3 levels of lumbar intervertebral disc prolapse confirmed by clinical and appropriate radiological investigations like X-ray and MRI and these patients failed to respond to non-operative treatment for atleast 6 weeks. We excluded patients with multiple level disc prolapses, patients with vertebral fractures due to trauma, failed back syndrome, spinal metastases, and associated with other pathological conditions of spine. 30 patients were included in the study and were followed up for upto 1 year post-operatively. After approval from the Institutional Ethics Committee a valid informed consent was taken from patient or patient's attendant. Then adequate preoperative preparation was done and patients were taken for elective surgery. All patients underwent standard laminectomy with discectomy. Surgical procedure included a mid-line vertical incision over the affected interspace of $6-8 \mathrm{~cm}$. after deep dissection, the laminae are carefully nibbled and the ligamentum flavum is removed using a Kerrison rongeur. After the cord has been exposed adequately the dura is retracted medially and nerve root is inspected. The nerve root is retracted medially using a blunt dissector in order to visualize the underlying disc. It may be seen as an extruded fragment or a bulging posterior longitudinal ligament. Cottonoid patties are used to tamponade the epidural veins once the root is retracted. If an extruded fragment is not seen the posterior longitudinal ligament is carefully examined for any defect or hole in the ligament, laterally. Gently the disc fragments are removed using disc forceps until the bulge has been decompressed. Gel foam is placed over the cord. The wound is closed in layers over a suction drain. Patient were evaluated clinically Postoperatively, X-rays (standard antero-posterior and lateral views) were taken. The patients were discharged on post-op day eleven after suture removal. They were later reviewed at 3, 6, 12 weeks and then at six months and 1 year. At discharge, six months and 1 year the functional outcome was assessed as per the Back Pain function scale (BPFS) of Strafford et al. .

\section{RESULTS}

Of 30 patients, 23 were males, 7 were females with mean age of $43.53 \pm 12.78$ years (Graph 1). Average duration of symptoms before surgery was $8.62 \pm 3.86$ months. Most of the patients were labourer by occupation (46.7\%) (Graph 2). Low back pain and radiculopathy was the most common symptoms with which the patients presented (100\%). Other complaints were weakness over lower limb (86.7\%) and paresthesia (40\%) (Graph 3). On examination, most common sign was positive Straight Leg Raising Test (SLRT) (100\%) followed by Paraspinal Muscle Spasm with Obliterated Lumbar Lordosis (90\%), restricted spinal movements $(76.7 \%)$, motor deficits $(53.3 \%)$ and sensory deficits (36.7\%) (Graph 4). Left side was mostly involved $(43.3 \%)$ followed by right side radiculopathy $(36.7 \%)$ and bilateral involvement (20\%). (Graph 5). L4-5 was the most common disc involved (80\%) (Table 1). Majority of the patients $(73.3 \%)$ presented with protrusion followed by extrusion (16.7\%) and sequestration (10\%) (Table 2). According to Back Pain Functional Scale, good results were found in $20(66.7 \%)$ cases, fair result in $6(20 \%)$ cases and poor results in $4(13.3 \%)$ cases at discharge. During 6 months follow-up period, good results were found in 25 $(83.3 \%)$ cases, fair result in $5(16.7 \%)$ cases and none of the patients had poor results (Graph 6). During 1-year follow-up period, all patients showed good results. $3(10 \%)$ patients had complications - 2 (6.7\%) patients had superficial surgical site infection and $1(3.3 \%)$ patient had dural tear. 

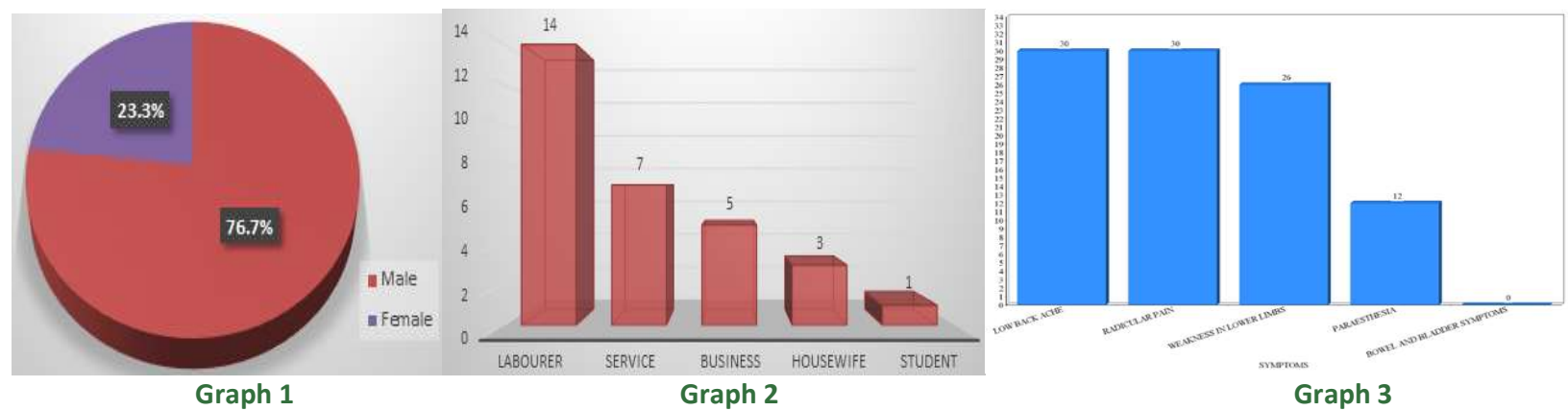

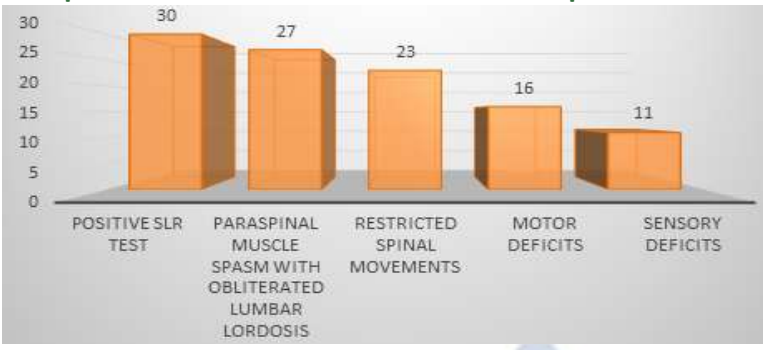

Graph 4

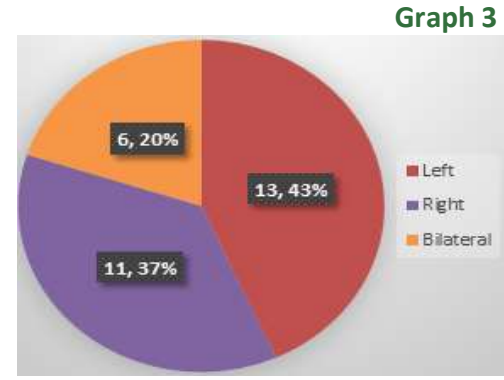

Graph 5

Graph 1: Distribution of patients according to Sex; Graph 2: Distribution of patients according to Occupation; Graph 3: Distribution of patients according to Symptoms; Graph 4: Distribution of patients according to signs; Graph 5: Distribution of patients according to side of lower limb involvement

Table 1: Distribution of patients according to Level of disc prolapse

\begin{tabular}{ccc}
\hline Level of disc prolapse & $\mathbf{N}$ & $\%$ \\
\hline L2-3 & 1 & $3.3 \%$ \\
L3-4 & 1 & $3.3 \%$ \\
L4-5 & 24 & $80 \%$ \\
L5-S1 & 4 & $13.3 \%$ \\
\hline Total & 30 & $100 \%$ \\
\hline
\end{tabular}

Table 2: Distribution of patients according to Type of disc prolapse

\begin{tabular}{ccc}
\hline Type of disc prolapse & $\mathrm{N}$ & $\%$ \\
\hline Protrusion & 22 & $73.3 \%$ \\
Extrusion & 5 & $16.7 \%$ \\
Sequestration & 3 & $10 \%$ \\
\hline Total & 30 & $100 \%$ \\
\hline
\end{tabular}

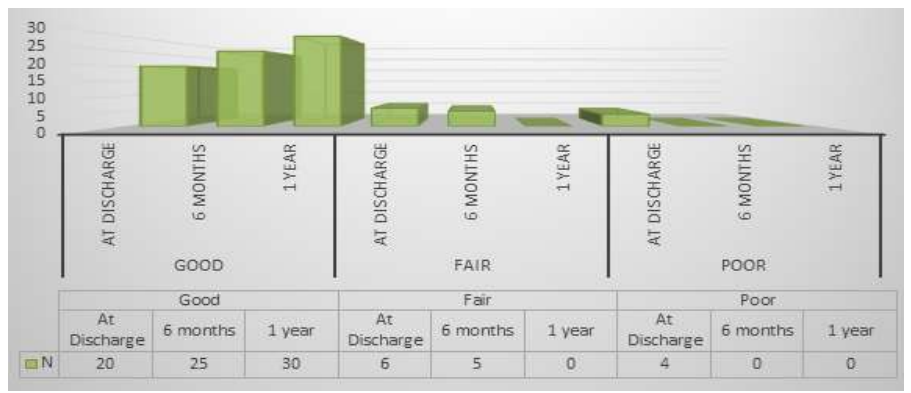

Graph 6: Functional Outcome of patients during Follow-up Period

\section{DISCUSSION}

We prospectively followed 30 patients for evaluating functional outcome of lumbar prolapsed intervertebral disc managed with surgical decompression. Majority of patients were male belonging to heavy manual labour group. These findings were similar to studies of Mittal A et al. ${ }^{5}$ ( $80 \%$ male, $20 \%$ female), Singh H et al. ${ }^{6}$ (65\% male, $35 \%$ female), Swamy A et al. ${ }^{7}$ (72\% males, $28 \%$ females) and Chakrabarty PS et al. ${ }^{8}$ (68\% males, $32 \%$ females). Singh $\mathrm{H} \mathrm{et} \mathrm{al.}{ }^{6}$ in their prospective study found majority of patients being manual labours (62.5\%), Sangwan SS et al. ${ }^{9}$ 
in their study observed that $90 \%$ of patients belonged to labour group, Mishra SK et al. ${ }^{10}$ in their study on 67 patients found $60 \%$ (40 patients) were involved in heavy work. The results of our study and other studies suggest that lumbar PIVD is more common among males who are manual labourers performing heavy work. It was observed in the present study that left side was mostly involved $(43.3 \%)$ followed by right side radiculopathy $(36.7 \%)$ and bilateral involvement (20\%). This is concordant to the study of Singh $\mathrm{H}$ et al. $^{6}$ in which left side was most commonly involved (42.5\%). The commonest level of disc prolapse in our study was found to be L4-5 (80\%). Swamy A et al. ${ }^{(7)}$ conducted a study on 50 patients of which $4(8 \%)$ patients had prolapsed intervertebral disc at L2-L3 level and $10(20 \%)$ patients had disc prolapsed at L3-L4 level, $22(44 \%)$ patients had disc prolapsed at L4-L5 level and 14 (28\%) patients had disc prolapsed at L5-S1 level. Singh H et al. ${ }^{6}$ in their prospective study observed L4-5 level was most commonly involved level (72.5\%). Mittal A et al. ${ }^{5}$ randomised prospective analysis observed commonest level of disc prolapse was found to be L-4-L5 (80.5\%). Above findings from our and other similar studies suggest L4-5 is the most common level of involvement in lumbar PIVD. It was observed in the present study that majority of the patients $(73.3 \%)$ presented with protrusion. This is similar to the study of Singh $\mathrm{H}$ et al. ${ }^{6}$ Who found protrusion in $82.5 \%$ patients on MRI. In our study, $3(10 \%)$ patients had complications - $2(6.7 \%)$ patients had superficial surgical site infection and $1(3.3 \%)$ patient had dural tear. Singh $\mathrm{H}$ et al. ${ }^{6}$ found complication rate was only $10 \%$ out of which 2 patients $(5 \%)$ had superficial surgical site infection and 2 patients (5\%) had dural tear. Sangwan SS et al. ${ }^{6}$ study on Lumbar disc excision reported dural tears in 3 cases, retention urine in 3 cases and transient back pain in 5 patients. They had none case of superficial skin infection, neurological disorder and nerve root injury. Wankhade UG et al. ${ }^{11}$ study reported complications in 4 $(08 \%)$ cases, among them 1 had dural tear while $3(6 \%)$ cases had superficial wound infection. The end point of assessment of any therapeutic modality is functional outcome, because that is what matters to the patients. However, the fact is that the good outcome varies from 49$90 \%$ in different studies. This only implies that there should be many factors which influence the outcome ${ }^{12}$. According to Manohara B et al, functional outcome of laminectomy with discectomy results were as good in $90 \%$ patients, fair in $6.2 \%$ patients and poor in $3.8 \%$ cases ${ }^{(13)}$. Similarly, Nahar et al.., showed good to excellent results in $80.42 \%$ cases, fair results in $17.2 \%$ and poor results in $2.17 \%$ cases $^{14}$. While Garg et al., observed good results among $86 \%$ cases while fair results in $12 \%$ and poor results in $2 \%$ cases ${ }^{15}$. In our study According to Back Pain Functional Scale, good results were found in 20 (66.7\%) cases, fair result in $6(20 \%)$ cases and poor results in 4 (13.3\%) cases at discharge. During 6 months follow-up period, good results were found in $25(83.3 \%)$ cases, fair result in $5(16.7 \%)$ cases and none of the patients had poor results. During 1 year follow-up period, all patients showed good results. This variation in studies may be due to different selection criteria of patients.

\section{CONCLUSION}

Most of the patients benefitted from lumbar discectomy surgery in terms of rapid reduction of pain. Our study established that functional outcome of lumbar prolapsed intervertebral disc managed with surgical decompression has a satisfactory functional outcome and improvement in the patients' quality of life with minimum complications.

\section{REFERENCES}

1. Mathew AC, Safar RS, Anithadevi TS, Banu MS, Shankar SL, Rai B, et al.. The prevalence and correlates of low back pain in adults: A cross sectional study from Southern India. International Journal of Medicine and Public Health. 2013;3(4):342-6.

2. Mixter WJ, Barr JS: Rupture of the intervertebral disc with involvement of spinal canal. N Engl J Med, 1934;211:215

3. Maetzel A, Li L. The economic burden of low back pain: a review of studies published between 1996 and 2001. Best Pract Res Clin Rheumatol. 2002, 16(1):23-30.

4. Cherkin DC, Deyo RA, Loeser JD et al. . An international comparison of back surgery rates. Spine. 1994, 19:12016.

5. Mittal A, Chandrasekhar A, Mohan R et al.. Analysis of the Functional Outcome of Discectomy in Lumbar Disc Prolapse. IOSR Journal of Dental and Medical Sciences. 2015; 14( 5: VI): 73-80.

6. Singh H, Bhavsar PB, Singh Aet al.. Functional outcome of patients undergoing lumbar discectomy. Int $\mathrm{J}$ Res Orthop 2018;4:514-8.

7. Swamy A, Swamy A, Sharma Ket al.. Functional Outcome of Discectomy for Lumbar Disc Prolapse. Journal of Spine. 2017;6(4).

8. Chakrabarty PS. Excision of lumber disc through fenestration: A Prospective study to analyse functional results. Ind J Med Res Pha Sci.2015; 2(1): 10-13

9. Sangwan SS, Kundu ZS, Singh R et al. Lumbar disc excision through fenestration. Ind $\mathrm{J}$ Orthop. 2006;40(2):86-89

10. Mishra SK,Pradhan NK et al..Lumbar disc excision:Comparative study of laminectomy and interlaminar fenestration.Indian J Orthopedics 1998;32(3):153-5

11. Wankhade UG, Umashankar MT, Jayakrishna Reddy BS. Functional Outcome of Lumbar Discectomy by Fenestration Technique in Lumbar Disc Prolapse - Return to Work and Relief of Pain. Journal of Clinical and Diagnostic Research. 2016, 10(3): RC09-RC13

12. Waddell G, McCulloch JA, Kummel E, Venner RM. Non organic physical signs in low back pain. Spine. $1980 ; 5(2): 117-25$. 
13. Manohara Babu KV. Surgical management of Lumbar disc prolapse by Fenestration technique. J.Orthopaedics. 2006;3(4):e6.

14. Nahar K, Srivastava RK. Prospective study of prolapsed lumbar intervertebral disc treatment by fenestration. Int $\mathbf{J}$ Res Med. 2013;2(2):170-73.
15. Garg M, Kumar S. Interlaminar discectomy and selective foraminotomy in lumbar disc herniation. J Orth Surg. 2001;9:15-18.

\section{Source of Support: None Declared Conflict of Interest: None Declared}

Policy for Articles with Open Access:

Authors who publish with MedPulse International Journal of Orthopedics, (Print ISSN: 2579-0889, Online) (ISSN: 2636-4638) agree to the following terms: Authors retain copyright and grant the journal right of first publication with the work simultaneously licensed under a Creative Commons Attribution License that allows others to share the work with an acknowledgement of the work's authorship and initial publication in this journal.

Authors are permitted and encouraged to post links to their work online (e.g., in institutional repositories or on their website) prior to and during the submission process, as it can lead to productive exchanges, as well as earlier and greater citation of published work. 